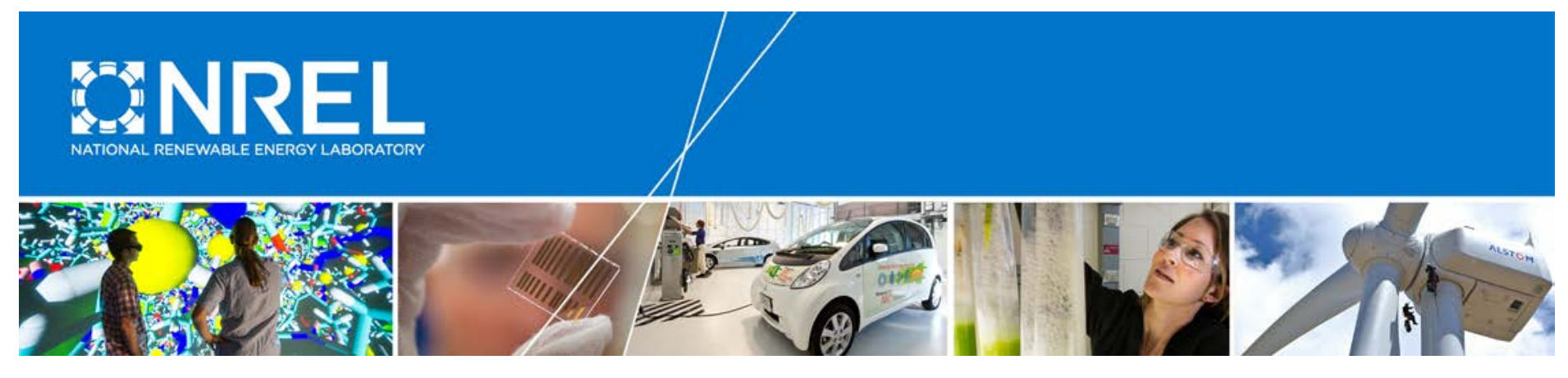

\title{
Application of the Most Likely Extreme Response Method for Wave Energy Converters
}

\section{Preprint}

Eliot Quon, Andrew Platt, Yi-Hsiang Yu, and Michael Lawson

National Renewable Energy Laboratory

Presented at the $35^{\text {th }}$ International Conference on Ocean, Offshore and Arctic Engineering (OMAE 2016)

Busan, South Korea

June 19-24, 2016

NREL is a national laboratory of the U.S. Department of Energy

Office of Energy Efficiency \& Renewable Energy

Operated by the Alliance for Sustainable Energy, LLC

This report is available at no cost from the National Renewable Energy

Laboratory (NREL) at www.nrel.gov/publications.

Conference Paper

NREL/CP-5000-65926

July 2016

Contract No. DE-AC36-08G028308 


\section{NOTICE}

The submitted manuscript has been offered by an employee of the Alliance for Sustainable Energy, LLC (Alliance), a contractor of the US Government under Contract No. DE-AC36-08GO28308. Accordingly, the US Government and Alliance retain a nonexclusive royalty-free license to publish or reproduce the published form of this contribution, or allow others to do so, for US Government purposes.

This report was prepared as an account of work sponsored by an agency of the United States government. Neither the United States government nor any agency thereof, nor any of their employees, makes any warranty, express or implied, or assumes any legal liability or responsibility for the accuracy, completeness, or usefulness of any information, apparatus, product, or process disclosed, or represents that its use would not infringe privately owned rights. Reference herein to any specific commercial product, process, or service by trade name, trademark, manufacturer, or otherwise does not necessarily constitute or imply its endorsement, recommendation, or favoring by the United States government or any agency thereof. The views and opinions of authors expressed herein do not necessarily state or reflect those of the United States government or any agency thereof.

This report is available at no cost from the National Renewable Energy Laboratory (NREL) at www.nrel.gov/publications.

Available electronically at SciTech Connect http:/www.osti.gov/scitech

Available for a processing fee to U.S. Department of Energy and its contractors, in paper, from:

U.S. Department of Energy

Office of Scientific and Technical Information

P.O. Box 62

Oak Ridge, TN 37831-0062

OSTI http://www.osti.gov

Phone: 865.576.8401

Fax: 865.576.5728

Email: reports@osti.gov

Available for sale to the public, in paper, from:

U.S. Department of Commerce

National Technical Information Service

5301 Shawnee Road

Alexandria, VA 22312

NTIS http://www.ntis.gov

Phone: 800.553 .6847 or 703.605 .6000

Fax: 703.605.6900

Email: orders@ntis.gov 


\section{OMAE2016-54751}

\section{APPLICATION OF THE MOST LIKELY EXTREME RESPONSE METHOD FOR WAVE ENERGY CONVERTERS}

\author{
Eliot Quon \\ National Renewable Energy Laboratory \\ Golden, CO 80401 \\ Email: Eliot.Quon@nrel.gov \\ Yi-Hsiang Yu* \\ National Renewable Energy Laboratory \\ Golden, CO 80401 \\ Email: Yi-Hsiang.Yu@nrel.gov
}

\author{
Andrew Platt \\ National Renewable Energy Laboratory \\ Golden, CO 80401 \\ Email: Andrew.Platt@nrel.gov \\ Michael Lawson \\ National Renewable Energy Laboratory \\ Golden, CO 80401 \\ Email: Michael.Lawson@nrel.gov
}

\begin{abstract}
Extreme loads are often a key cost driver for wave energy converters (WECs). As an alternative to exhaustive Monte Carlo or long-term simulations, the most likely extreme response (MLER) method allows mid- and high-fidelity simulations to be used more efficiently in evaluating WEC response to events at the edges of the design envelope, and is therefore applicable to system design analysis. The study discussed in this paper applies the MLER method to investigate the maximum heave, pitch, and surge force of a point absorber WEC. Most likely extreme waves were obtained from a set of wave statistics data based on spectral analysis and the response amplitude operators (RAOs) of the floating body; the RAOs were computed from a simple radiation-and-diffraction-theory-based numerical model. A weakly nonlinear numerical method and a computational fluid dynamics (CFD) method were then applied to compute the shortterm response to the MLER wave. Effects of nonlinear wave and floating body interaction on the WEC under the anticipated 100year waves were examined by comparing the results from the linearly superimposed RAOs, the weakly nonlinear model, and CFD simulations. Overall, the MLER method was successfully applied. In particular, when coupled to a high-fidelity CFD analysis, the nonlinear fluid dynamics can be readily captured.
\end{abstract}

${ }^{*}$ Address all correspondence to this author.

\section{KEYWORDS}

Wave energy; extreme conditions; most likely extreme response; computational fluid dynamics

\section{INTRODUCTION}

The extreme wave-induced loads that wave energy converters (WECs) experience during both operational and survival sea states are often the key cost driver for WEC designs $[1,2]$. As a result, it is essential to find an efficient pathway to reduce the cost of energy for the WEC industry to be successful. In particular, the effect of nonlinear complex wave and floating body interactions significantly influences the prediction of survival sea state design loads. The prediction of those loads is a critical step in the design process, and the application of mid- and highfidelity numerical methods (e.g., weakly-nonlinear-based models and computational fluid dynamics [CFD] simulations [3]) and experimental wave tank tests are often needed. Because the extreme load is a stochastic event and its occurrence is a matter of chance caused by the body's instantaneous position and a series of random waves, statistical analyses are commonly used to determine the extreme design load [4].

The rapid improvement of computing technology has made mid- and high-fidelity numerical methods available for design applications; however, the required computational time is still long for statistical analysis to search through all essential wave environments in which extreme loads are most likely to occur. 
To improve the model efficiency and reduce required computational time, the shipping and offshore industry often perform their mid- and high-fidelity simulations and experimental wave tank tests using an equivalent design wave profile generated from (linear) low-fidelity model solutions [5]. The equivalent design waves represent the sea state at which the extreme loads are most likely to occur. Several methods have been used for numerical and experimental naval architecture studies, including the most likely wave (MLW), most likely extreme response (MLER), most likely response wave (MLRW), conditional random response wave (CRRW) [6,7], and design load generator [8] approaches. These methods assume the nonlinear response of a floating vessel can be approximated by a linearized response, and the nonlinear response is a small perturbation from the linear solution.

Yu et al. [9] applied a similar approach to develop a framework for analyzing WEC extreme design loads. The study included a series of Monte-Carlo-type linear time-domain simulations to determine the sea state at which extreme loads occur and a set of CFD simulations in regular waves with a statistically determined 100-year maximum wave height. Still, the method did not account for the influence from the body instantaneous position and the series of random waves.

The objective of this paper is to improve the modeling framework and methodology used for predicting the WEC design load under survival wave conditions. The MLER method was applied in the study to model a floating ellipsoid. MLER waves were generated from the extreme wave statistics data and the linear response amplitude operators (RAOs) were obtained from a simple radiation-and-diffraction-method-based numerical model known as the Wave Energy Converter Simulator, or WECSim. The resulting waves were then used in the nonlinear WECSim and CFD simulations. For this study, the high-fidelity CFD analysis was performed using an unsteady Reynolds-averaged Navier-Stokes (URANS) methodology, Star-CCM+. The maximum heave and pitch and the peak surge force were analyzed. We compared the results from linear RAO-based solutions to those from nonlinear WEC-Sim and Star-CCM+ simulations to examine the influence of nonlinear wave-body interaction on the floating body dynamics. Finally, a discussion on further applications of the MLER method for extreme condition modeling is presented.

\section{MODEL GEOMETRY AND TEST CONFIGURATIONS}

The body tested in this study is an ellipsoid with a cross section characterized by semimajor and semiminor axes of $5.0 \mathrm{~m}$ and $2.5 \mathrm{~m}$ in the wave propagation and normal directions, respectively (Fig. 1). The ellipsoid is at its equilibrium position with its origin located at the mean water surface. The mass of the body is set to $1.342 \times 10^{5} \mathrm{~kg}$, and the center of gravity is located $2 \mathrm{~m}$ below the origin. As shown in Fig. 1, two test configurations were considered in the study. In Configuration A, we only allowed the body to move freely in heave. In Configuration B, the body is allowed to rotate around its center of gravity in addition to the

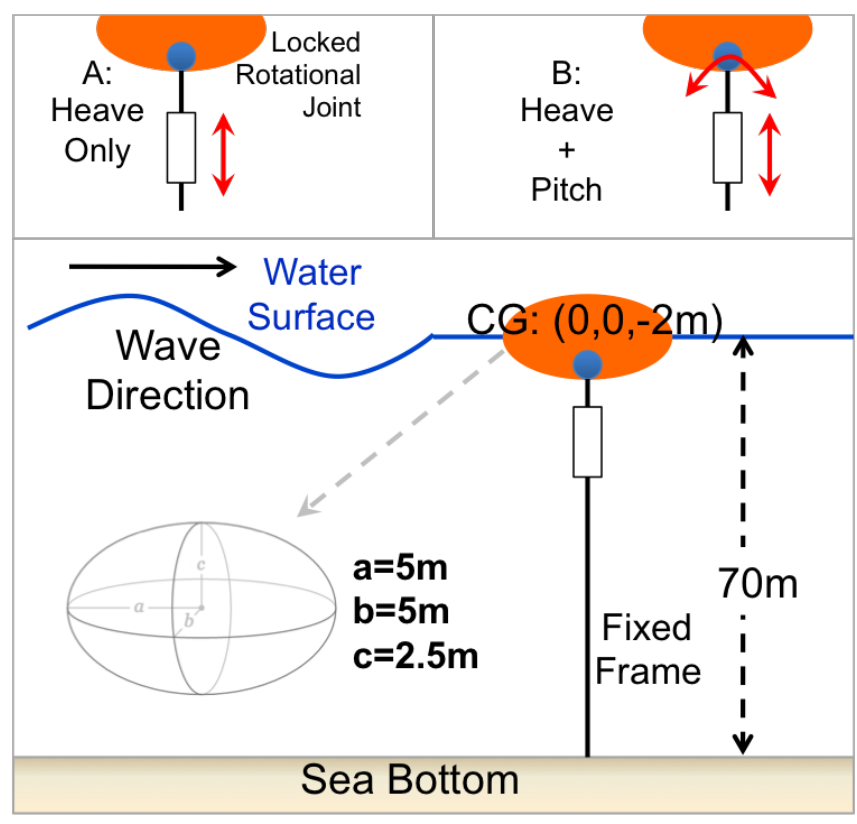

FIGURE 1. SIDE VIEW OF THE NOTIONAL POINTABSORBER WEC EVALUATED IN THIS STUDY; CONFIGURATIONS A AND B AND THEIR ASSOCIATED DEGREES OF FREEDOM ARE ILLUSTRATED IN THE TOP LEFT AND RIGHT BOXES.

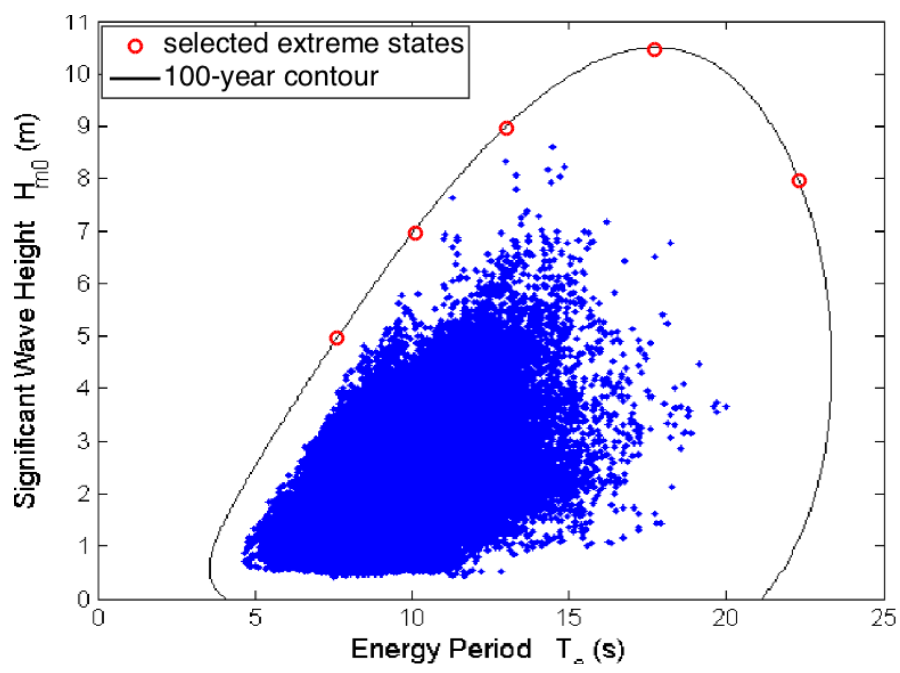

FIGURE 2. ONE-HUNDRED-YEAR CONTOUR FROM THE COASTAL DATA INFORMATION PROGRAM STATION AND NATIONAL DATA BUOY CENTER BUOY (ADOPTED FROM [10]).

heave motion specified in Configuration A. Heave and pitch degrees of freedom were considered because these displacements are typically limited with an end stop in power take-off (PTO) systems. For simplicity, the behavior of the PTO system was not modeled. 
TABLE 1. WAVE ENVIRONMENTS ALONG THE 100-YEAR CONTOUR FROM THE COASTAL DATA INFORMATION PROGRAM STATION AND NATIONAL DATA BUOY CENTER BUOY.

\begin{tabular}{|c|c|c|c|}
\hline Case & Significant & Energy & Peak \\
\hline Number & Wave Height Hs & Period Te & Period Tp \\
\hline 1 & $5 \mathrm{~m}$ & $7.6 \mathrm{~s}$ & $8.2 \mathrm{~s}$ \\
\hline 2 & $7 \mathrm{~m}$ & $10.1 \mathrm{~s}$ & $11.7 \mathrm{~s}$ \\
\hline 3 & $9 \mathrm{~m}$ & $13 \mathrm{~s}$ & $15.1 \mathrm{~s}$ \\
\hline 4 & $10.5 \mathrm{~m}$ & $17.7 \mathrm{~s}$ & $20.5 \mathrm{~s}$ \\
\hline 5 & $8 \mathrm{~m}$ & $22.3 \mathrm{~s}$ & $25.9 \mathrm{~s}$ \\
\hline
\end{tabular}

\section{EXTREME SEA STATES}

For the extreme wave environment, we used the wave statistics data based on the measurements from the Coastal Data Information Program \#128 station and the National Data Buoy Center \#46212 buoy near Humboldt Bay, California. The latter is one of the potential wave energy test sites in the United States. Figure 2 shows the sea state measurements and the estimated 100-year contour [10]. We then selected five representative wave environments along the 100-year contour to perform our short-term response analysis using the MLER method, listed in Tab. 1.

\section{METHODOLOGY}

To generate the wave profile that produces the largest likely response of the WEC device, the RAO is calculated using linear WEC-Sim for each of the degrees of freedom of interest. The RAO is then combined with the Brettschneider spectrum, which corresponds to each of the five extreme wave environments listed in Tab. 1, using the MLER method to produce the underlying wave profile that leads to the largest response in each degree of freedom. The resulting wave profile is then used in nonlinear WEC-Sim and high-fidelity URANS simulations to fully model the system's nonlinear hydrodynamics. This section describes all the numerical methods used in the study, including the MLER, WEC-Sim, and URANS methods.

\section{Most Likely Extreme Response}

The MLER method uses the linear RAO of the device and the spectrum for the sea state of interest to produce a wave profile that gives the largest response. Because it uses linear theory, the underlying assumption is that the higher-order effects are small in comparison to the linear effects. Starting with a wave time series described by

$$
Z(t)=\sum_{n=1}^{N} a_{z, n}\left[V_{n} \cos \left(\omega_{n} t-k_{n} x\right)+W_{n} \sin \left(\omega_{n} t-k_{n} x\right)\right]
$$

where $a_{z, n}$ is the spectral amplitude, $\sqrt{S\left(\omega_{n}\right) \Delta \omega}$, and the coefficients $V_{n}$ and $W_{n}$ are independent standard normal random variables containing white Gaussian noise and phase randomization. The corresponding response can be written as

$$
\begin{array}{r}
\zeta(t)=\sum_{n=1}^{N} a_{z, n}\left|\Phi_{\mathrm{R}, n}\right|\left[V_{n} \cos \left(\omega_{n} t-k_{n} x+\theta_{\mathrm{R}, n}\right)\right. \\
\left.+W_{n} \sin \left(\omega_{n} t-k_{n} x+\theta_{\mathrm{R}, n}\right)\right]
\end{array}
$$

where $\left|\Phi_{\mathrm{R}, n}\right|$ and $\theta_{\mathrm{R}, n}$ are the RAO magnitude and phase angle, respectively.

The incident wave profile that yields the largest response of the floating body can then be derived using information from the wave spectrum and the response spectrum to replace the values of $V_{n}$ and $W_{n}$. The response spectrum is calculated by combining the wave spectrum with the RAO of the body as

$$
S_{\mathrm{R}}\left(\omega_{n}\right)=\left|\Phi_{\mathrm{R}}\left(\omega_{n}\right)\right|^{2} S\left(\omega_{n}\right)
$$

where $\Phi_{R}\left(\omega_{n}\right)$ is the RAO for a given degree of freedom. Using this information and the derivations presented in Dietz [6] and Drummen [11], a set of equations are derived by way of a Slepian process to describe the reaction of a vessel to an incoming wave train. This yields a set of equations that describe the maximum response of the vessel conditioned by the RAO. New values for $V_{n}$ and $W_{n}$ conditioned with the vessel response spectrum are given as

$$
\begin{aligned}
& \bar{V}_{\mathrm{R}, n}=\left|\Phi_{\mathrm{R}, n}\right| M_{d} a_{z, n} \frac{\cos \left(\theta_{\mathrm{R}, n}\right)}{\left(m_{2} m_{0}-m_{1}^{2}\right)} \\
& \times {\left[\left(m_{2}-\omega_{n} m_{1}\right)+\bar{\omega}_{\mathrm{R}}\left(\omega_{n} m_{0}-m_{1}\right)\right] } \\
& \bar{W}_{\mathrm{R}, n}=\left|\Phi_{\mathrm{R}, n}\right| M_{d} a_{z, n} \frac{\sin \left(\theta_{\mathrm{R}, n}\right)}{\left(m_{2} m_{0}-m_{1}^{2}\right)} \\
& \times\left[\left(m_{2}-\omega_{n} m_{1}\right)+\bar{\omega}_{\mathrm{R}}\left(\omega_{n} m_{0}-m_{1}\right)\right]
\end{aligned}
$$

where $M_{d}$ is the desired response amplitude, $\bar{\omega}_{\mathrm{R}}=m_{1} / m_{0}$ of the response spectrum, and the response spectral amplitude defined as $a_{\mathrm{R}, n} \equiv\left|\Phi_{\mathrm{R}, n}\right| a_{z, n}$. The spectral moments of the response, $m_{0}$, $m_{1}$, and $m_{2}$, are given by

$$
m_{i}=\sum_{n=1}^{N} \omega_{n}^{i} S_{\mathrm{R}}\left(\omega_{n}\right) \Delta \omega \quad \text { where } \quad i=0,1,2,3, \ldots
$$

Replacing $V_{n}$ and $W_{n}$ in Eqn. (1) with Eqns. (4) and (5), and simplifying significantly, yields the underlying wave profile that will produce the largest response

$$
Z_{\mathrm{R}, c}(t)=\sum_{n=1}^{N} a_{z, n} M_{d} A_{\mathrm{R}, n} \cos \left(\omega_{n} t-k_{n} x-\theta_{\mathrm{R}, n}\right)
$$




$$
A_{\mathrm{R}, n} \equiv \frac{\left|\Phi_{\mathrm{R}, n}\right| a_{z, n}}{m_{0} m_{2}-m_{1}^{2}}\left[\left(m_{2}-m_{1} \omega_{n}\right)+\bar{\omega}_{\mathrm{R}}\left(m_{0} \omega_{n}-m_{1}\right)\right]
$$

The corresponding response from Eqn. (2) becomes

$$
\zeta_{\mathrm{R}, c}(t)=\sum_{n=1}^{N} M_{d} a_{z, n}\left|\Phi_{\mathrm{R}, n}\right| A_{\mathrm{R}, n} \cos \left(\omega_{n} t-k_{n} x\right)
$$

Note that the phase term present in the wave profile of Eqn. (7) is perfectly canceled out by the RAO phase giving a maximum response amplitude at $t=0$. It is important to note that this method produces a shaped wave profile that is independent of the desired magnitude of the response, $M_{d}$. Therefore, it can be rescaled to waves of different amplitudes for the purposes of generating short-term statistical loads. In this case, the peak values of the underlying wave amplitudes from Eqn. (7) were rescaled to simulate the maximum 100-year individual wave height, $\mathrm{H}_{100}$, for the starting sea state, which is most likely 1.9 times the significant wave height for the 100-year wave given in Tab. 1, assuming a storm lasts for 3 hours with 1000 waves [12].

\section{WEC-Sim}

WEC-Sim is an open-source system dynamics modeling tool developed for simulating multibody WECs [13]. The dynamic response is calculated by solving the equation of motion about its center of gravity, which can be given as

$$
\begin{aligned}
\left(m+A_{\infty}\right) \ddot{X}= & -\int_{0}^{t} K(t-\tau) \dot{X}(\tau) d \tau \\
& +F_{\text {ext }}+F_{\text {vis }}+F_{\text {res }}+F_{P T O}+F_{\text {moor }}
\end{aligned}
$$

where $A_{\infty}$ is the added mass matrix at infinite frequency, $X$ is the (translational and rotational) displacement vector of the body, $m$ is the mass matrix, $F_{\text {ext }}$ is the wave excitation force, $F_{P T O}$ is the force from the PTO system, $F_{m o o r}$ is the mooring force, $F_{v i s}$ is the viscous damping force vector, and $F_{\text {res }}$ is the net buoyancy restoring force. The convolution integral term, $-\int_{0}^{t} K(t-\tau) \dot{X}(\tau) d \tau$ is calculated following the Cummins' equation [14], where $K$ is the impulse response function.

In this study, the added-mass matrix, impulse response function, and diffraction component in $F_{\text {ext }}$ were computed using WAMIT [15], a frequency-domain potential flow solver. Linear WEC-Sim was used to compute the RAOs that were used in the MLER method. In linear WEC-Sim simulations, $F_{\text {res }}$ and the Froude-Krylov force component in $F_{\text {ext }}$, generated by the undisturbed incident waves, were also obtained from WAMIT. Nonlinear WEC-Sim was used to simulate the focused wave scenario and model the body system dynamics using the MLER method.

\begin{tabular}{ll}
\hline Pressure-velocity coupling & Transient SIMPLE algorithm \\
Time-marching scheme & Second-order implicit \\
Convection scheme & Second-order upwind \\
Free surface capturing & Volume of fluid model \\
Wave absorber & Sponge-layer damping zone \\
Device motion & Overset scheme \\
\hline
\end{tabular}

The nonlinear WEC-Sim followed a weakly nonlinear approach, in which the $F_{\text {res }}$ and Froude-Krylov force were computed by integrating the theoretical static and dynamic components of the hydrodynamic pressure for each panel along the wetted body surface at each time step [16]. Wheeler stretching was also applied through coordinate mapping for wave kinematics to satisfy the boundary condition on the water surface based on the instantaneous wave elevation [17].

\section{URANS Simulations}

A finite-volume URANS solver, StarCCM+ [18], was used to simulate focused waves defined by the MLER approach and model the body system's dynamic response. The method discretizes the time-accurate Navier-Stokes equations of motion over the computational domain and solves the system of linear equations in the time domain. This solver and numerical model were successfully applied previously for a heaving device in extreme regular waves [9]. The numerical settings used in this study are listed in Tab. 2. For simplicity, turbulence modeling was not employed and the fluid flow was assumed to be laminar. An overset methodology was applied to simulate device motion wherein two layers of meshes were implemented, one for the floating body subject to kinematic constraints and a second for simulating the background wave field. The two meshes are solved simultaneously to capture unsteady wave-body interactions. Figure 3 illustrates the present overset configuration. The stationary background mesh cells have been colored as inactive (cell type $=-1$ ), no solution performed; active (0), solution performed at each time step; donors (1), active, and provides a solution to the moving mesh; intermediate (2); and receptors (3), active, and receiving a solution from the moving mesh.

In the case of a focused wave, a single reference length (e.g., the wavelength) is not well defined. For this work, a characteristic length $(L)$ was chosen as the wavelength of the largest amplitude wave in the wave train, which has a frequency corresponding to the peak period. Spatial resolution near the water surface is 80 cells per $L$ in the downwave direction $\left(N_{x}=80\right)$ and 10 cells per $H_{s}$ in the normal direction $\left(N_{z}=10\right)$. This resulted in an aspect ratio of 4 (Fig. 3), and additional refinement was not performed in the normal direction to keep the aspect ratio $\sim \mathrm{O}(1)$. Grid resolution near the device was set to $0.25 \mathrm{~m}$, providing ap- 


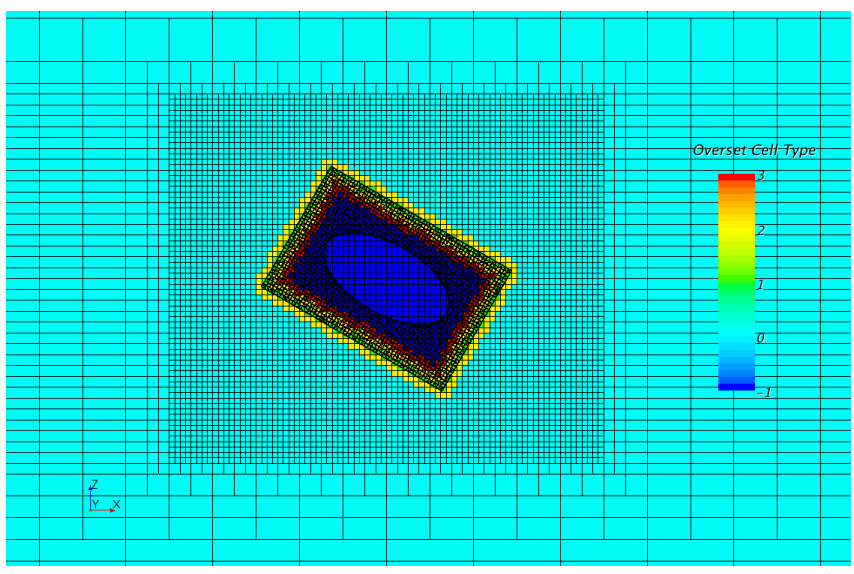

FIGURE 3. OVERSET MESH CONFIGURATION.

proximately 100 points along a surface cross-sectional curve. A water depth $(d)$ of $70 \mathrm{~m}$ was modeled. To absorb outgoing and reflected waves without generating additional numerical disturbances, a $1.5 \mathrm{~L}$-long damping zone was also included. The entire computational domain extended from $-600 \mathrm{~m}$ to $600+1.5 \mathrm{~L} \mathrm{~m}$ in the downwave $(x)$ direction, from $-L / 2$ to $L / 2$ in the lateral $(y)$ direction, and from $-d$ to $d$ in the vertical direction $(z)$.

The MLER wave spectra were specified as components of a linear superposition wave on the inflow boundary and used to initialize the solution on the interior of the computational domain. Time marching is performed with a second-order algorithm and a relatively small time-step size chosen to minimize temporal error. Using the reference length $L$ and the peak period $T_{p}$, a reference wave speed $(U)$ is obtained. An estimate of the maximum Courant number is therefore provided by $C=U \Delta t / \Delta x=(L \Delta t) /\left(T_{p} \Delta x\right)$ and a time-step size is selected to achieve $C \leq 0.25$. For this case, $\Delta t=0.02$ was chosen for an estimated $C \approx 0.12$, or 15,000 steps per $T_{p}$.

\section{SHORT-TERM RESPONSE}

The results from the MLER application study are presented in this section and include two sets of URANS simulations. First, a series of simulations for a single sea state (Case 3 - Configuration A) were performed without the float to assess mesh resolution requirements. Then, simulations for all five sea states selected along the 100-year contour (Tab. 1) were conducted using both Configurations A and B. The URANS results were compared to those from weakly nonlinear WEC-Sim simulations and theoretical solutions from linear RAOs.

\section{URANS Mesh Resolution Study}

A convergence study was performed to verify that the solution was not sensitive to discretization error and that the specified wave solution on the inlet boundary is able to propagate through the entire computational domain without accumulating significant numerical errors. Sea state 3 (Configuration A), characterized by a relatively steep, large amplitude, focused wave was

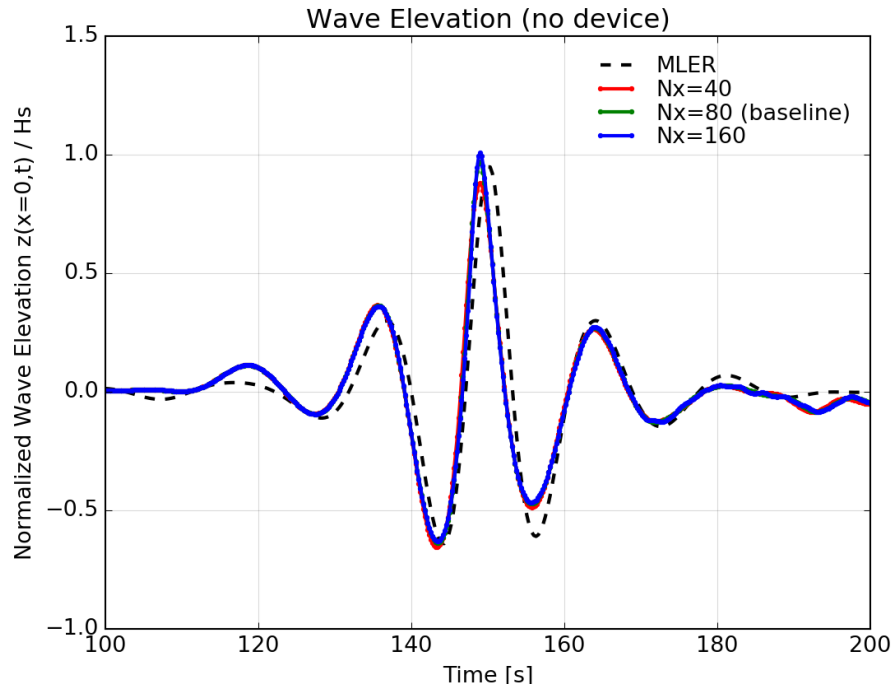

FIGURE 4. SENSITIVITY TO GRID REFINEMENT OF SEA STATE 3 (CONFIGURATION A) SIMULATED WITH URANS WITHOUT A DEVICE IN THE WATER.

TABLE 3. URANS MESH CONVERGENCE.

\begin{tabular}{lcccc}
\hline$N_{x}$ & $Z_{\max }$ & rel. error [\%] & $M_{0}$ & rel. error [\%] \\
\hline 40 & $7.90 \mathrm{~m}$ & - & 158.3 & - \\
80 & $8.73 \mathrm{~m}$ & $10.5 \%$ & 161.3 & $1.90 \%$ \\
160 & $9.06 \mathrm{~m}$ & $3.78 \%$ & 161.2 & $0.06 \%$ \\
\hline
\end{tabular}

simulated without a device in the water. URANS solutions for the propagated wave at three levels of grid refinement are plotted in Fig. 4 in comparison with the theoretical MLER result. The three URANS results show that numerical simulations are convergent $(N x=80$ and 160 curves are visually indistinguishable) and demonstrate excellent resolution of the peak location and amplitude. Although the linear MLER predicts a symmetric wave elevation profile, the URANS method permits asymmetry from the nonlinearity of steep waves. Table 3 shows the convergence of the maximum wave elevation $\left(Z_{\max }\right)$ and spectral content in terms of the zero ${ }^{\text {th }}$ spectral moment $\left(M_{0}\right)$, with the relative error defined as the change in a given quantity compared to the previous level of refinement. When using a baseline resolution of 80 cells per reference length $(N x=80)$, the spectral content is nearly invariant. Further refinement $(N x=160)$ reduces the relative error in wave height to $4 \%$, which does not justify the accompanying two-fold increase in computational cost. The baseline grid has been used for all subsequent simulations.

\section{MLER Applications}

The five sea states identified in Tab. 1 were simulated with the ellipsoid float geometry. For each case, Configurations A and 
TABLE 4. SUMMARY OF URANS SIMULATED RESULTS.

\begin{tabular}{ccccccc}
\hline & & $\begin{array}{c}\mathbf{Z}_{\max } \\
{[\mathrm{m}]}\end{array}$ & $\begin{array}{c}\zeta_{\max } \\
{[\mathrm{m}]}\end{array}$ & $\begin{array}{c}\theta_{\mathbf{m a x}} \\
{[\mathrm{deg}]}\end{array}$ & $\begin{array}{c}\mathbf{F}_{\mathbf{x}, \mathbf{m i n}} \\
{[\mathrm{kN}]}\end{array}$ & $\begin{array}{c}\mathbf{F}_{\mathbf{x}, \mathbf{m a x}} \\
{[\mathrm{kN}]}\end{array}$ \\
\hline & Sea 1A & 3.78 & 2.70 & 0 & -504 & 366 \\
& Sea 2A & 6.44 & 5.52 & 0 & -386 & 702 \\
Config. & Sea 3A & 8.73 & 7.89 & 0 & -460 & 607 \\
A & Sea 4A & 10.9 & 9.85 & 0 & -390 & 465 \\
& Sea 5A & 8.96 & 8.49 & 0 & -301 & 219 \\
\hline & Sea 1B & 3.69 & 3.37 & 29.0 & -602 & 690 \\
Config. & Sea 3B & 7.88 & 9.71 & 52.1 & -648 & 1238 \\
B & Sea 4B & 10.5 & 10.4 & 37.2 & -527 & 744 \\
& Sea 5B & 7.41 & 6.92 & 17.1 & -492 & 155 \\
\hline
\end{tabular}

B (with one and two degrees of freedom, respectively) were considered. The simpler case included only vertical motion (heave), whereas the latter permitted both heaving and pitching motion around the body's center of gravity. Two different sets of MLERfocused waves were generated for the two float configurations. In Configuration A, the RAO was conditioned to achieve the maximum heave response, whereas in Configuration B the RAO was conditioned for maximum pitch response. The focused waves in the latter cases were steeper, with a maximum wave elevation occurring prior to the instant of maximum response.

Results for all calculations are summarized in Tab. 4. With only heave motion, the largest displacement $\left(\zeta_{\max }\right)$ was observed in Sea State 4, whereas the largest surge force $\left(F_{x}\right)$ was observed in Sea State 2. In all cases, the float acted as a wave follower and the vertical displacement of the device never exceeded the surface elevation; however, when pitching motion was permitted the float dynamics changed significantly, and both the largest pitch $\left(\theta_{\max }\right)$ and maximum load were observed in Sea State 3. Configuration B saw significantly higher surge forces in nearly all cases because the device was constrained in the surge direction, and any nonzero pitch increased the frontal area of the float.

Overall trends for the different methodologies are illustrated in Figs. 5-7. The heave and pitch responses are normalized by the significant wave height $\left(H_{s}\right)$ and maximum wave slope angle, respectively. The maximum wave angle was directly evaluated from the MLER coefficients using the spatial derivative of Eqn. (7) and corresponds to the wave profile in the absence of the device.

In the heave-only configuration (Configuration A), the weakly nonlinear WEC-Sim and fully nonlinear URANS simulations showed that the amplitude of the device response was reduced for steep and short-period focused MLER waves (Fig. 5).

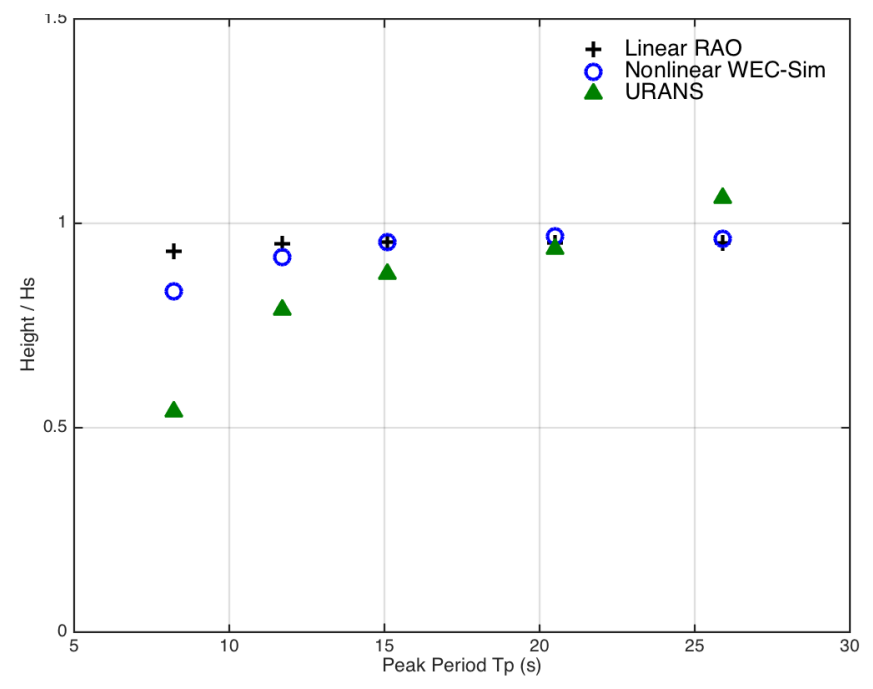

FIGURE 5. COMPARISON OF (NORMALIZED) HEAVE RESPONSE FOR CONFIGURATION A.

For peak periods $\leq 15 \mathrm{~s}$, the URANS response is between 65 $92 \%$ of the weakly-nonlinear response. For peak periods larger than $20 \mathrm{~s}$, the heave responses of the device are similar to those obtained from the linear RAO and nonlinear WEC-Sim approaches.The larger URANS heave response in Sea State 5 corresponds to an increased wave crest height associated with relatively shallow water. The nondimensional depth, $d / g T_{p}^{2}$, was an order of magnitude smaller in Sea State 5 compared to Sea State 1 , which lies in the deep water regime.

Figure 6 illustrates the heave response for Configuration $\mathrm{B}$, which permits both heaving and pitching motion. The normalized heave responses predicted by the linear RAO and nonlinear WEC-Sim are very similar. As before, the linear RAO slightly overpredicts the heave response for short peak periods. In contrast, the URANS calculations predict significantly different trends. The three regions that have been highlighted in Fig. 6 correspond to three different dominant physical behaviors. In Region 1, the relatively short peak period corresponds to a very steep wave that exceeds the breaking wave limit of $H_{s} / L_{r e f} \approx 0.14$. The URANS simulations for Seas $1 \mathrm{~B}$ and $2 \mathrm{~B}$ capture the wave breaking, which disrupts the wave train and alters both the wave peak amplitude and location; these responses cannot be directly compared to the linear RAO and nonlinear WEC-Sim. Simulations in Region 2 do not break but exhibit strong fluid-body interactions that are captured by URANS; in contrast, the linear RAO and nonlinear WEC-Sim do not account for the deformation of the wave surface caused by the device motion. Finally, Region 3 simulations approximate wave-follower behavior and similar results between all methods are expected.

The most notable differences between the various simulation methods were observed in the pitch response for Configuration B (Fig. 7). Because the float orientation is expected to approximately track the wave elevation profile, pronounced maxima and minima in pitch were observed prior to and after the focused wave passage; both follow distinct trends and therefore 


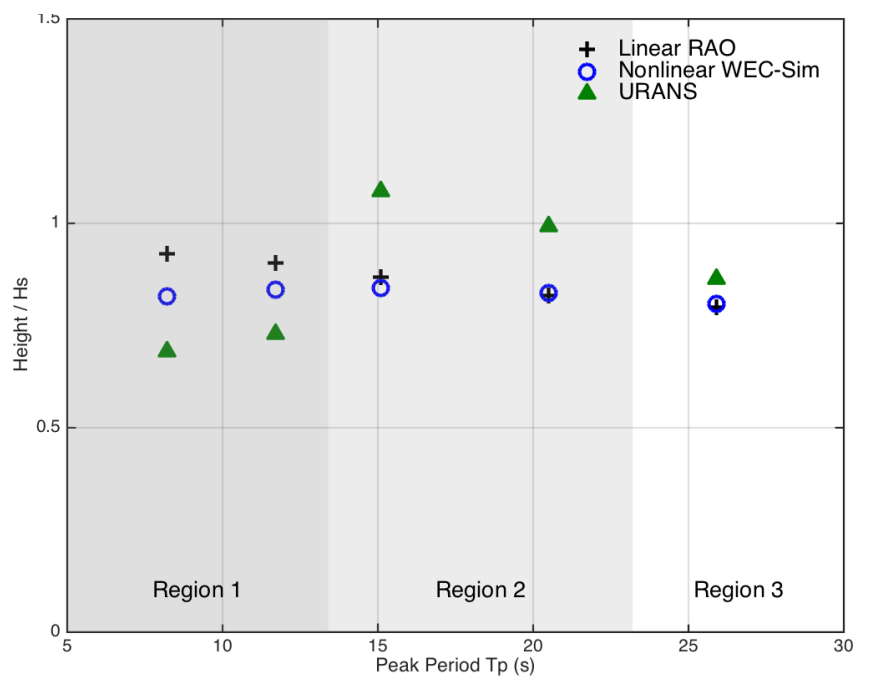

FIGURE 6. COMPARISON OF (NORMALIZED) HEAVE RESPONSE FOR CONFIGURATION B.

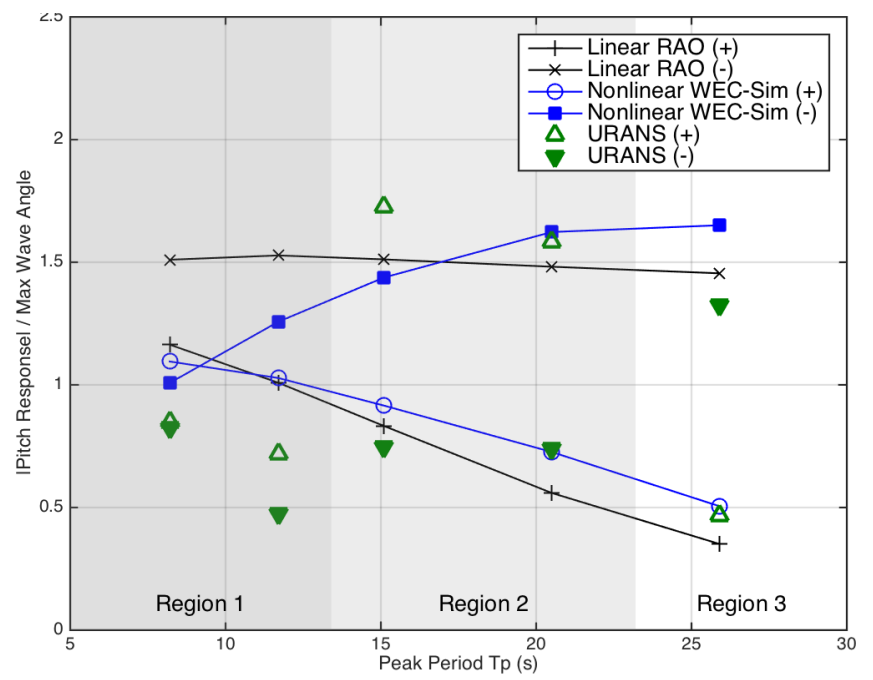

FIGURE 7. COMPARISON OF (NORMALIZED) PITCH RESPONSE FOR CONFIGURATION B; (+) AND (-) DENOTE THE MAXIMUM POSITIVE AND NEGATIVE RESPONSES.

have been presented. In the linear case, the maximum pitch response is approximately 1.5 times the maximum wave surface elevation slope, and nearly invariant across all sea states. The secondary response is a maximum for Sea State $1 \mathrm{~B}$, which has the steepest focused wave; this response decreases linearly with the peak period. As with the heave response in Configuration A, the weakly nonlinear WEC-Sim model tends to reduce the amplitude of the maximum response for shorter-period sea states. Both the primary and secondary weakly nonlinear WEC-SIM pitch responses are larger than predicted by the linear RAO, but maintain the same trend for longer peak periods.

To further elucidate the float response under the various sea states, traces of the wave surface elevation at the device location and the device responses are plotted for Sea States 3 and 5 in

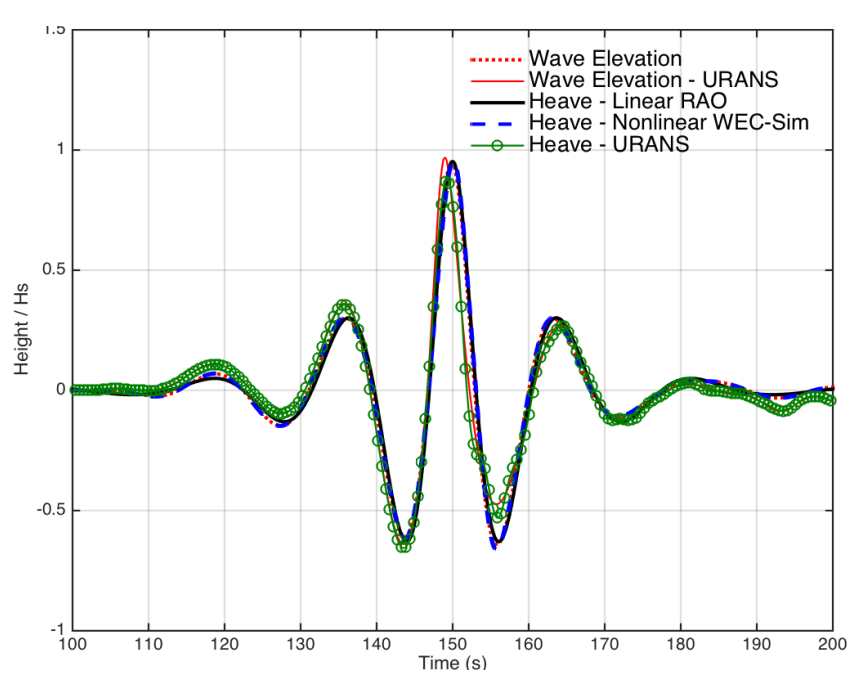

(a) Heave response - configuration $\mathrm{A}$

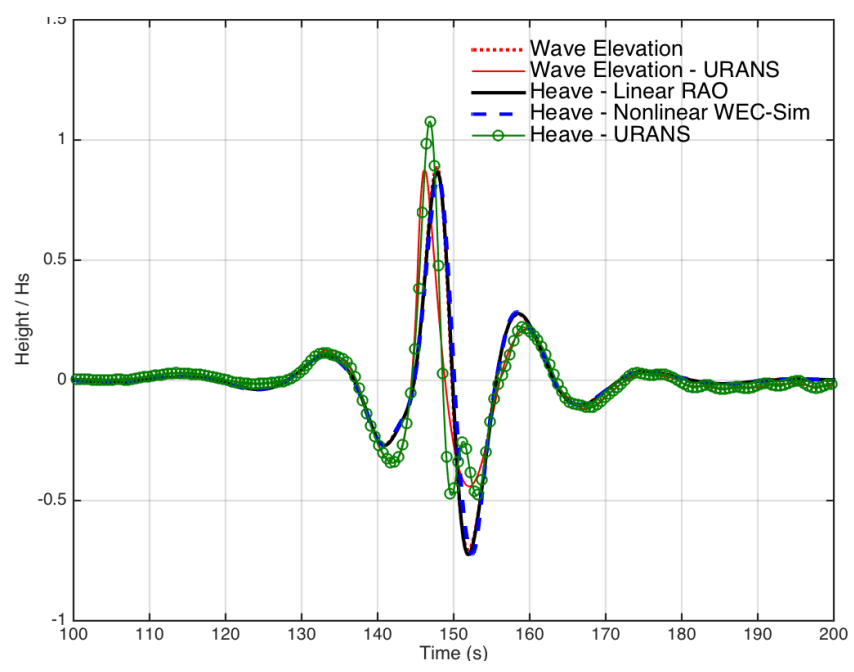

(b) Heave response - configuration B

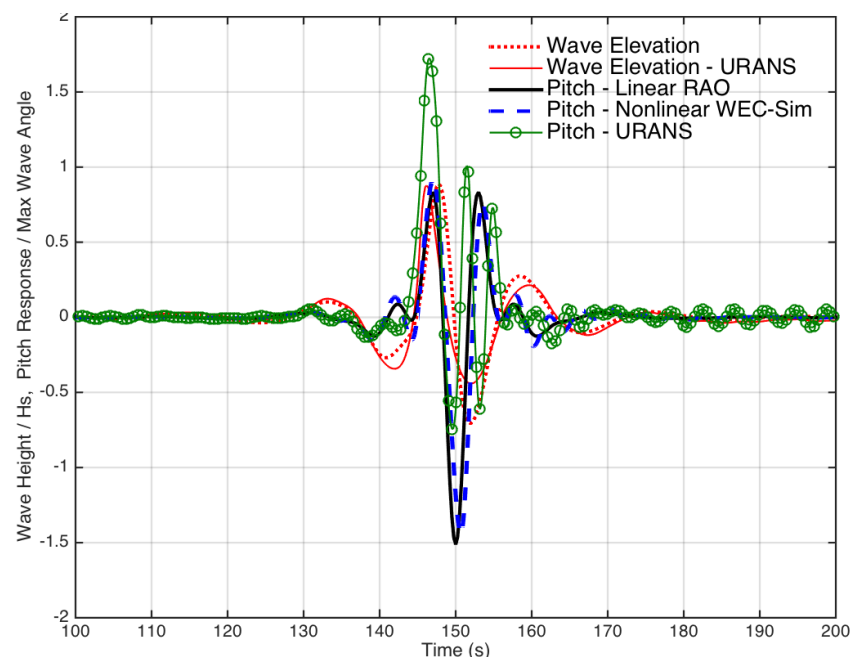

(c) Pitch response - configuration B

FIGURE 8. RESULTS FOR SEA STATE $3\left(H_{s}=9 \mathrm{~m} ; T_{p}=15.1 \mathrm{~s}\right)$. 


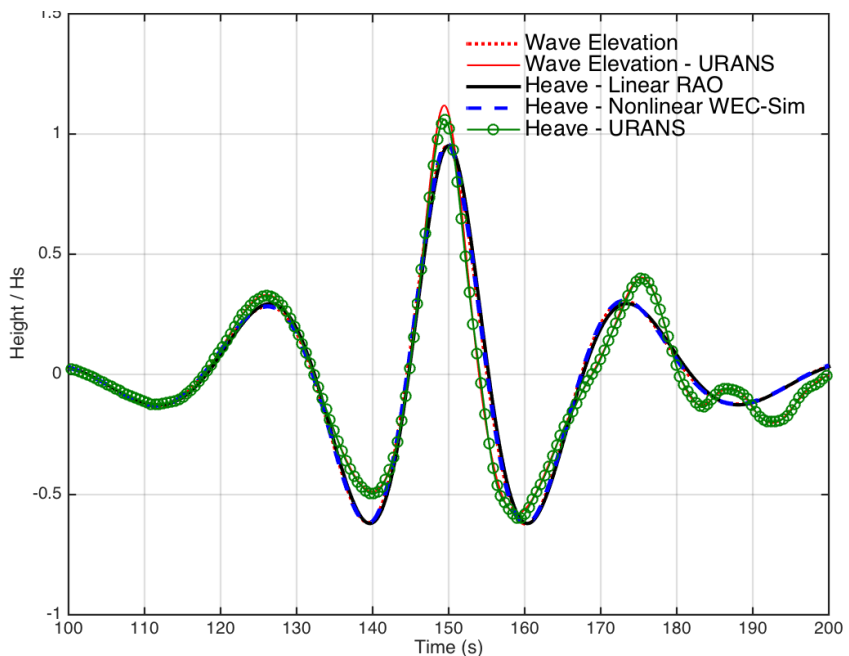

(a) Heave response - Configuration $\mathrm{A}$

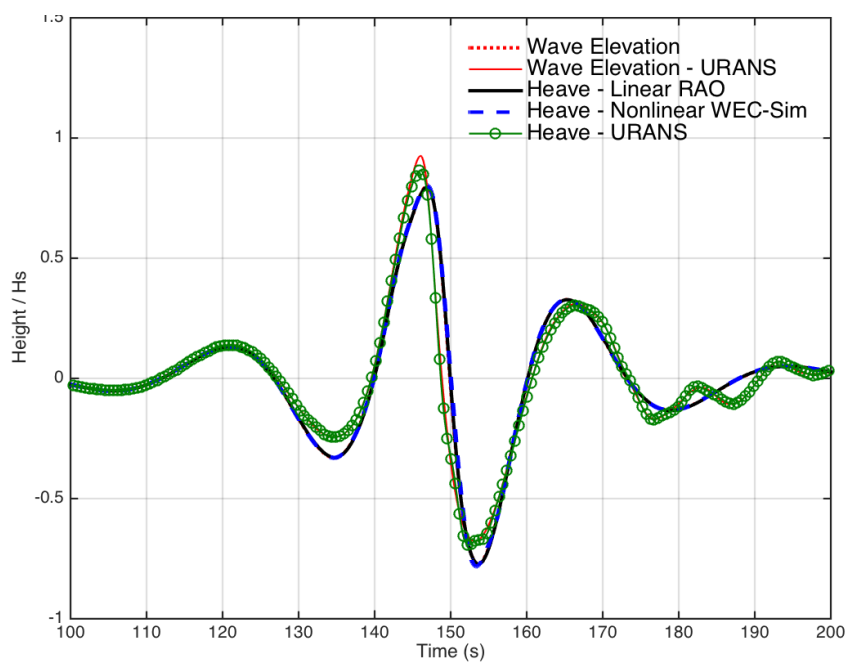

(b) Heave response - Configuration B

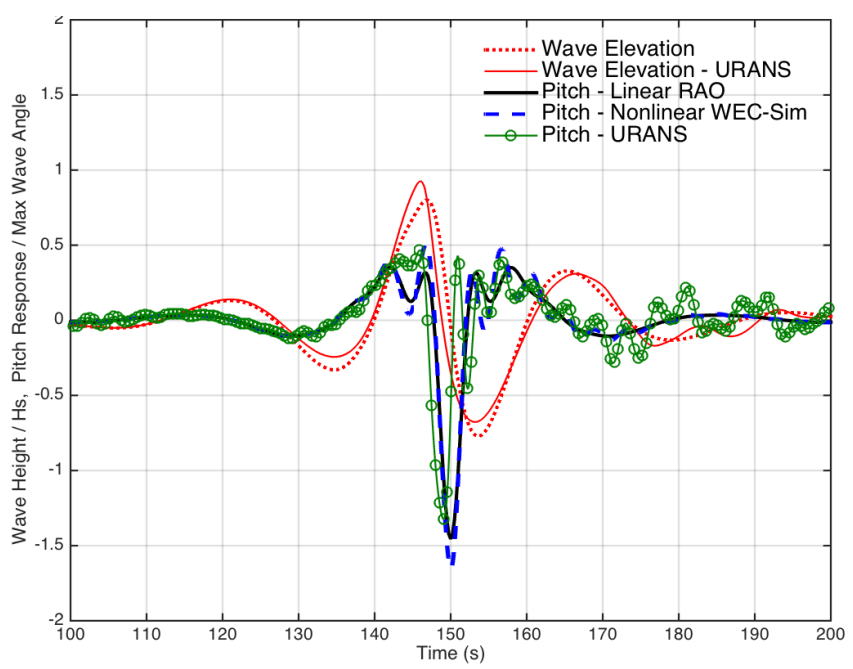

(c) Pitch response - Configuration B

FIGURE 9. RESULTS FOR SEA STATE $5\left(H_{s}=8 \mathrm{~m} ; T_{p}=25.9 \mathrm{~s}\right)$.
Figs. 8 and 9. For Configuration $\mathrm{A}$ in both sea states, the float response never deviated significantly from the simulated wave elevation, acting as a wave follower. In Configuration B, the input wave spectra were designed to produce the peak pitch response at $t=150 \mathrm{~s}$. As expected, the linear RAO and nonlinear WECSim simulations reflected this for both cases, predicting a maximum response where the wave slope was a maximum; however, from both the heave and pitch responses in Sea State 3 (Fig. 8), the URANS responses for Configuration B deviated significantly from wave-follower behavior because of nonlinear fluid-body interactions. The peak pitch response occurred about $3 \mathrm{~s}$ earlier, coinciding with the passage of the focused wave crest. As shown in Fig. 10, the float was partially out of the water and the body pitch response exceeded the range of linear approximation. These differences between methodologies are expected because the wave field was altered by the motion of the body, a situation that is not considered in the nonlinear WEC-Sim model.

In Sea State 5, the URANS response shows good agreement with the other methodologies (Fig. 9). The float exhibits wave-follower behavior at all stages of the wave-train passage (Fig. 11): the maximum and minimum heave response correspond to the passage of the focused wave crest and trough, respectively, and the maximum pitch response occurs near the instant at which the focused wave slope is a maximum.

\section{DISCUSSION}

The study demonstrated the use of the MLER method to evaluate the dynamic response of an ellipsoid float under 100year extreme waves. Figure 12 shows the snapshots of water surface and the pressure distribution on the float for Configuration B in Sea State 3. The application of the MLER method provided a simple and efficient approach to evaluate the nonlinear extreme response for the floating body, particularly when coupled with a high-fidelity CFD simulation, in which highly nonlinear effects on the system dynamics can be captured. High-resolution pressure distribution on the body surface data can then be utilized for high-fidelity structural analyses.

In this study, Configuration A was used for verification, because the float heave response generally followed the wave elevation. The nonlinear wave-body interaction effect was essential only in Sea State 1, where waves were relatively steep. On the other hand, the pitch motion in Configuration B resulted in significant nonlinear interactions between the waves and the float. The MLER waves maximized the wave slope so that the maximum pitch motion for the float was most likely to occur. Because the waves along the 100-year wave contour were steep, particularly for shorter period sea states, test cases need to be carefully selected to avoid the occurrence of wave breaking if that is not essential to the response of interest.

Note that the maximum pitch angle was greater than 30 degrees for Configuration B in Sea States 1-3, which was beyond the limitations for linear theory. The inclusion of nonlinear restoring and Froude-Krylov forces in nonlinear WEC-Sim, based on the instantaneous free surface, were effective for captur- 


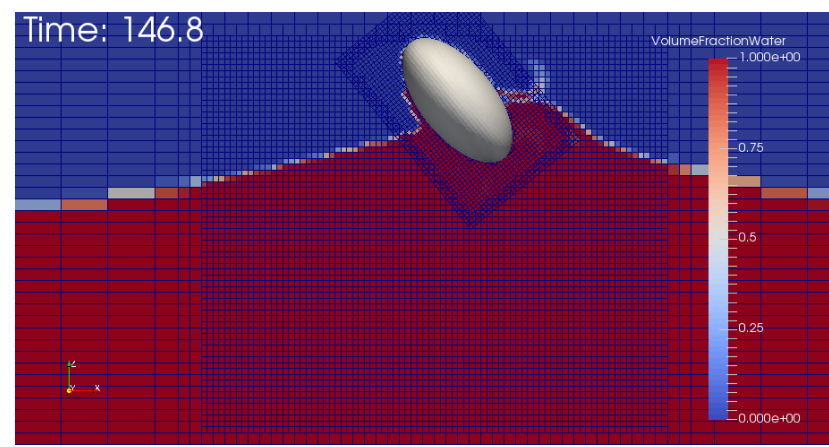

(a) Maximum heave and pitch response $(t=146.8 \mathrm{~s})$

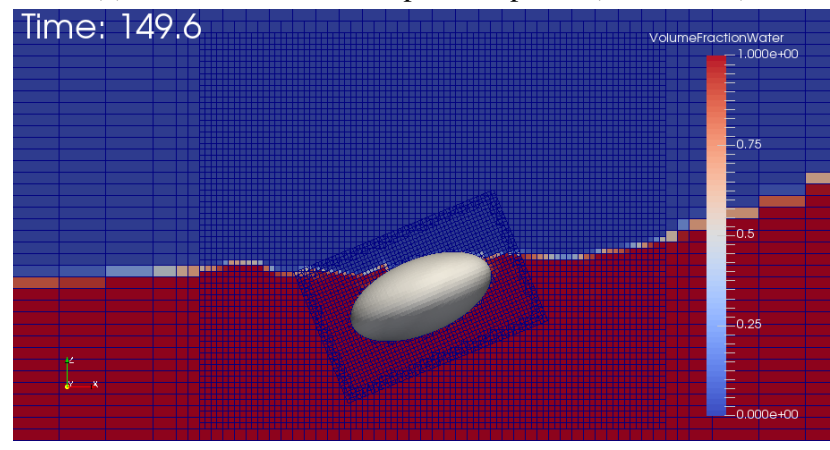

(b) Minimum heave response $(t=149.6 \mathrm{~s})$

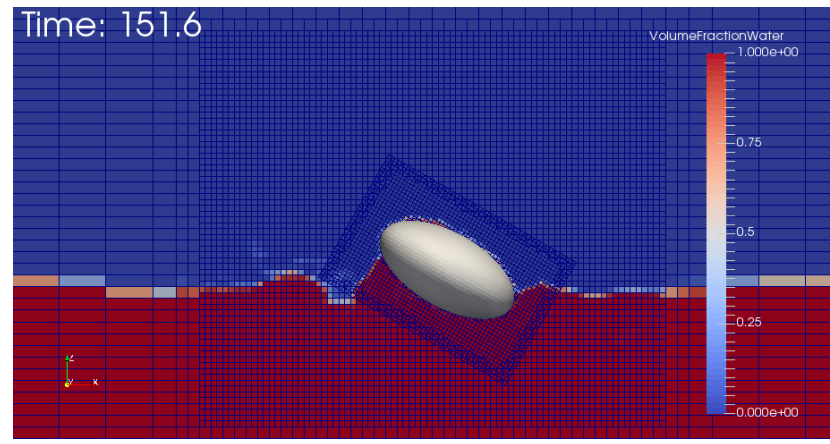

(c) Subsequent pitching response $(t=151.6 \mathrm{~s})$

FIGURE 10. CONTOURS OF THE VOLUME FRACTION OF WATER FOR SEA STATE 3, CONFIGURATION B.

ing the weakly nonlinear wave-body interaction. Still, the nonlinear WEC-Sim model did not consider the influence of body motion on the water surface and failed to capture its effect on the body dynamics.

The MLER method was applied successfully in this study; however, this type of equivalent design wave method has been shown to be less accurate when the load response depends heavily on the instantaneous wave train, vessel position, and its deformation, unless a random background wave was used [7]. U1timately, these methods may work well for some responses of interest but not for others, depending on the WEC design and working principle. Further analysis is needed to evaluate the accuracy of the equivalent design wave approach, particularly for cases in which complex nonlinear wave-body interactions are essential.

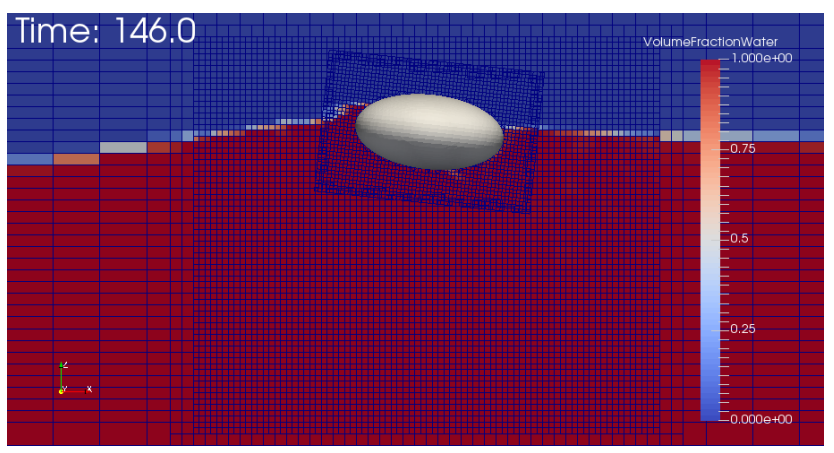

(a) Maximum heave response $(t=146.0 \mathrm{~s})$

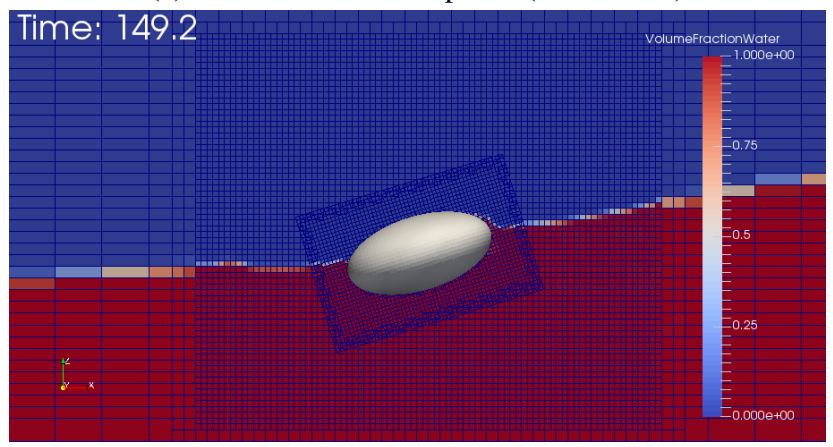

(b) Minimum heave response ( $t=149.2 \mathrm{~s})$

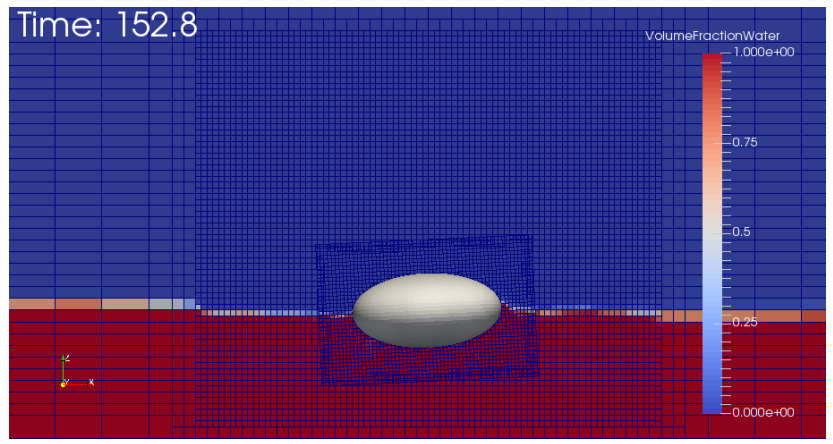

(c) Minimum heave response $(t=152.8 \mathrm{~s})$

FIGURE 11. CONTOURS OF THE VOLUME FRACTION OF WATER FOR SEA STATE 5, CONFIGURATION B.

\section{CONCLUSIONS}

The MLER approach demonstrates a viable methodology for identifying and analyzing extreme loads within the design process. When coupled to a high-fidelity CFD analysis, nonlinear fluid dynamics may be readily captured even with simplified kinematics. Moreover, the device response to events at the edges of the design envelope may be evaluated using a short-term analysis. This analysis can potentially reduce the need for longterm simulations or tank tests that require the generation of thousands of wave events, thereby providing significant cost savings. Future work will include longer simulations to further validate and motivate application of the MLER/URANS approach. Additional investigations into the accuracy of the URANS methodology will be performed, particularly in Region 2 where strong fluid-body interactions were observed. Finally, the influence 

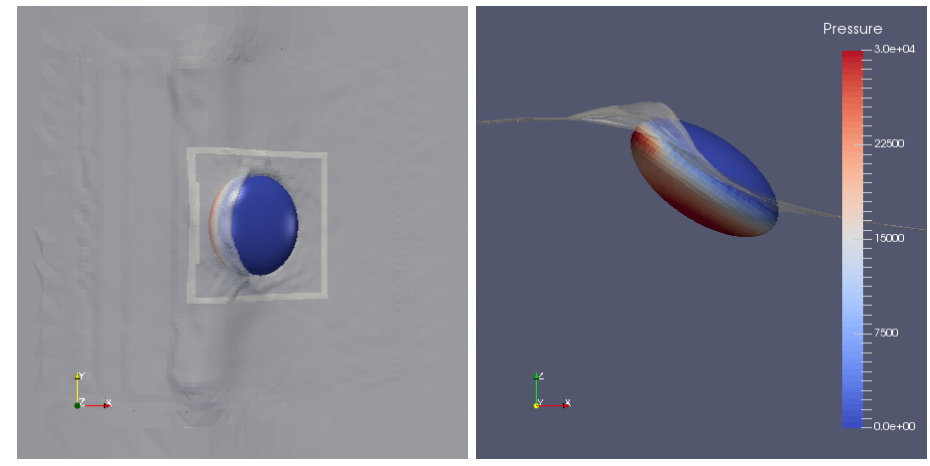

(a) Maximum positive surge force $(t=145.6 \mathrm{~s})$
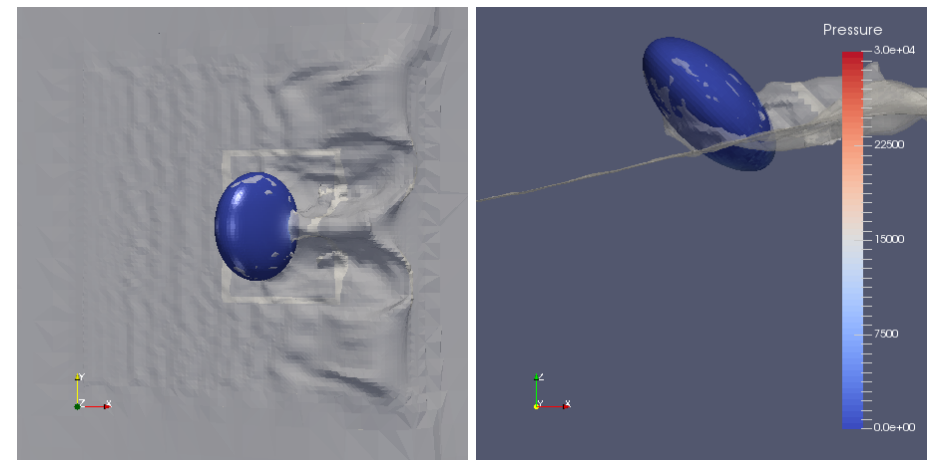

(b) Float out of water $(t=147.2 \mathrm{~s})$
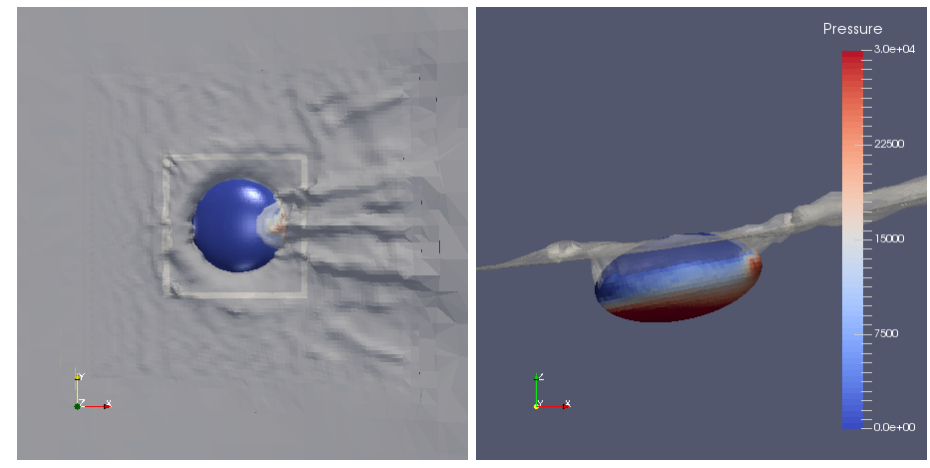

(c) Maximum negative surge force $(t=148.8 \mathrm{~s})$
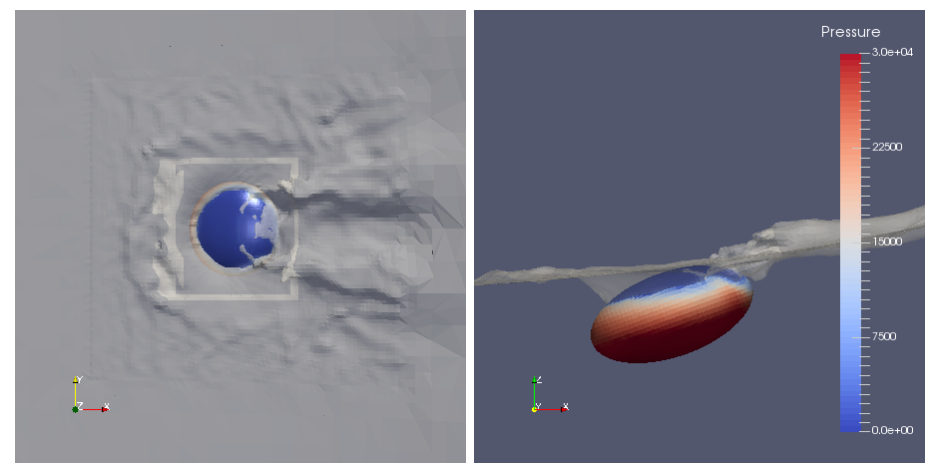

(d) Maximum heave force $(t=149.2 \mathrm{~s})$

FIGURE 12. VISUALIZATION OF THE SEA SURFACE IN SEA STATE 3, CONFIGURATION B; FLOAT SURFACE IS COLORED BY PRESSURE. of including additional degrees of freedom will be considered and more detailed structural response analysis will be performed through coupling with finite-element analysis methods.

\section{ACKNOWLEDGMENT}

This work was supported by the U.S. Department of Energy under Contract No. DE-AC36-08GO28308 with the National Renewable Energy Laboratory. Funding for the work was provided by the DOE Office of Energy Efficiency and Renewable Energy, Wind and Water Power Technologies Office.

\section{REFERENCES}

[1] Neary, V. S., Previsic, M., Jepsen, R. A., Lawson, M. J., Yu, Y.-H., Copping, A. E., Fontaine, A. A., Hallett, K. C., and Murray, D. K., 2014. Methodology for Design and Economic Analysis of Marine Energy Conversion (MEC) Technologies, Sandia National Laboratories, Albuquerque, NM, USA.

[2] Jenne, D. S., Yu, Y.-H., and Neary, V., 2015. "Levelized Cost of Energy Analysis of Marine and Hydrokinetic Reference Models," In 3rd Marine Energy Technology Symposium, METS, Washington, DC, USA.

[3] Li, Y., and Yu, Y.-H., 2012. "A Synthesis of Numerical Methods for Modeling Wave Energy Converter-Point Absorbers," Renewable and Sustainable Energy Reviews, 16(6), pp. 4352-4364.

[4] Coe, R. G., Neary, V. S., Lawson, M. J., Yu, Y., and Weber, J., 2014. Extreme Conditions Modeling Workshop Report, National Renewable Energy Laboratory (NREL), Golden, CO, USA.

[5] Ley, J., Amian, C., Shigunov, V., Rathje, H., Oberhagemann, J., Langer, M., and Schellin, T. E., 2013. "Green Water Loads on a Cruise Ship," In 32nd International Conference on Ocean, Offshore and Arctic Engineering, OMAE, Nantes, France.

[6] Dietz, J. S., 2004. "Application of Conditional Waves as Critical Wave Episodes for Extreme Loads on Marine Structures". PhD thesis, Technical University of Denmark.

[7] Drummen, I., Wu, M., and Moan, T., 2009. "Numerical and experimental investigations into the application of response conditioned waves for long-term nonlinear analyses," $\mathrm{Ma}$ rine Structures, 22(3), jul, pp. 576-593.

[8] Kim, D.-H., and Troesch, A. W., 2014. "Statistical Estimation of Extreme Roll Responses in Short Crested Irregular Head Seas," Society of Naval Architects and Marine Engineers Transactions.

[9] Yu, Y.-H., Van Rij, J., Coe, R., and Lawson, M., 2015. "Preliminary Wave Energy Converters Extreme Load Analysis," In 34th International Conference on Ocean, Offshore and Arctic Engineering, OMAE, St. John's, Newfoundland, Canada.

[10] Dallman, A. R., and Neary, V. S., 2014. Characterization of U.S. Wave Energy Converter (WEC) Test Sites: A Cat- 
alogue of Met-Ocean Data, Sandia National Laboratories, Albuquerque, NM, USA.

[11] Drummen, I., Wu, M., Kaminski, M. L., and Moan, T., 2009. "Numerical investigation into the application of response conditioned waves for long-term nonlinear fatigue analyses of rigid hulls," Ocean Engineering, 36, pp. 12081216.

[12] Det Norske Veritas, 2010. Recommended Practice: Environmental Conditions and Environmental Loads, DNV.

[13] Yu, Y.-H., Lawson, M., Ruehl, K., and Michelen, C., 2014. "Development and Demonstration of the WEC-Sim Wave Energy Converter Simulation Tool," In 2nd Marine Energy Technology Symposium, Seattle, WA, USA.

[14] Cummins, W., 1962. The Impulse Response Function and
Ship Motions, David Taylor Model Dasin (DTNSRDC).

[15] Lee, C., and Newman, J., 2015. WAMIT User Manual Version 7.1.

[16] Tom, N., Lawson, M., and Yu, Y.-H., 2015. "Demonstration of the Recent Additions in Modeling Capabilities for the WEC-Sim Wave Energy Converter Design Tool," In 34th International Conference on Ocean, Offshore and Arctic Engineering, OMAE, St. John's, Newfoundland, Canada.

[17] Wheeler, J. D., and Others, 1969. "Methods for calculating forces produced by irregular waves," In Offshore Technology Conference, Offshore Technology Conference.

[18] CD-adapco, 2014. User guide STAR-CCM+ Version 9.04. 